\title{
Nosectomia em felinos portadores de carcinoma espinocelular - Relato de sete casos
}

\author{
Nosectomy in cats with squamous cell carcinoma - Seven cases \\ report
}

\author{
Rafael Ricardo Huppes ${ }^{1}$; Andrigo Barboza de Nardi²; \\ Ricardo Andres Ramirez Uscategui ${ }^{3 *}$; Josiane Morais Pazzini ${ }^{4}$; \\ Jorge Luiz Costa Castro ${ }^{5}$
}

\section{Resumo}

O carcinoma de células escamosas é um tumor maligno dos queratinócitos, o diagnostico definitivo desta doença se baseia no exame histopatológico das lesões. As narinas dos gatos é uma das regiões comumente afetadas por esta neoplasia. A resposta aos agentes quimioterapêuticos, criocirurgia e radioterapia não é muito promissora, por este motivo a ressecção cirúrgica é instituída a fim de remover a maior quantidade de tecido comprometido e proporcionar margens cirúrgicas livres, nos casos de envolvimento nasal, realiza-se nosectomia, muitas vezes precisando utilizar técnicas reconstrutivas como os flapes de avanço para a síntese das feridas cirúrgicas. Devido a grande incidência de pacientes felinos com esta entidade, o presente estudo objetiva relatar e discutir a eficácia da nosectomia em sete felinos acometidos pela doença. Conclui-se que a nosectomia é uma técnica com fim terapêutica, eficaz em cinco dos setes pacientes felinos, resseccionando a massa tumoral com margem e proporcionando tempo e qualidade de vida aceitável.

Palavras-chave: Gato, narinas, flape, cirurgia reconstrutiva

\begin{abstract}
Squamous cell carcinoma is a keratinocytes malignant tumor, the definitive diagnosis of this disease is based on histopathology examination of the lesions. The cats nostrils is one of regions commonly affected by this neoplasm. The response to chemotherapeutic agents, cryosurgery and radiotherapy is poor and for this reason surgical resection is instituted for remove the greatest amount of tissue engaged and provide free margins, in case of nasal involvement are indicated nosectomy often needing reconstructive techniques using as advance flaps for synthesis of surgical wounds. Due to the high incidence of feline patients with this entity, this study aims to report and discuss the effectiveness of nosectomy in seven cats with the disease. It is concluded that nosectomy as a therapeutic technique effective in five of seven cats, resecting tumor margin and providing acceptable time and quality life.

Key words: Cat, nostrils, flap, reconstructive surgery
\end{abstract}

\footnotetext{
${ }^{1}$ Discente do Programa de Pós-Graduação em Medicina Veterinária, no curso de Doutorado da Faculdade de Ciências Agrárias e Veterinárias, Universidade Estadual Paulista, FCAV/UNESP, Jaboticabal, SP. E-mail: rafaelhuppes@hotmail.com

${ }^{2}$ Prof. do Dept ${ }^{\circ}$ de Clínica e Cirurgia Veterinária, FCAV/UNESP, Jaboticabal, SP. E-mail: andrigobarboza@yahoo.com.br

${ }^{3}$ Discente do Programa de Pós-Graduação em Cirurgia Veterinária, no curso de Doutorado da Faculdade de Ciências Agrárias e Veterinárias, FCAV/UNESP, Jaboticabal, SP. E-mail: ramirezuscategui@hotmail.com

${ }^{4}$ Discente do Programa de Pós-Graduação em Cirurgia Veterinária, no curso de Mestrado da Faculdade de Ciências Agrárias e Veterinárias, FCAV/UNESP, Jaboticabal, SP. E-mail: josipazzini@hotmail.com

${ }^{5}$ Prof. do Curso de Medicina Veterinária da Pontifícia Universidade Católica do Paraná, PUCPR, Curitiba, PR. E-mail: castrojlc@ gmail.com

* Autor para correspondência
} 


\section{Introdução}

O carcinoma de células escamosas (CCE) é um tumor maligno dos queratinócitos. É também conhecido como carcinoma espinocelular ou epidermóide (FERREIRA et. al., 2006). A etiologia ainda permanece desconhecida, no entanto, alguns autores descrevem que a exposição aos raios ultravioletas seja a causa principal da ocorrência desta neoplasia (MURPHY; MARTIN; MIHM, 2000; KRAEGEL; MADEWELL, 2004).

As regiões mais afetadas pelo carcinoma de células escamosas são tronco, orelhas, pálpebras, narinas, lábios, região inguinal e axilar (RODASKI; WERNER, 2009). As lesões destas neoplasias podem se apresentar de formas variadas como proliferativa ou erosiva (SCOTT; MILLER; GRIFFIN, 2001).

Segundo Ferreira et al. (2006) a precocidade no diagnóstico é fundamental no prognóstico e inicialmente, as lesões são proliferativas, hiperêmicas, crostosas e posteriormente evoluem para úlceras com invasão de tecidos adjacentes.

O diagnóstico definitivo é baseado na anamnese, exame físico, biopsia e confirmado pelo exame histopatológico. No que diz respeito aos tratamentos existem várias modalidades incluindo criocirurgia e quimioterapia, porém os melhores resultados são observados com a cirurgia e raditerapia. Porém, a escolha da modalidade terapêutica deve ser estabelecida de acordo com o estadiamento do tumor, o estado geral do paciente, a aceitação do proprietário em relação aos efeitos colaterais e às mudanças estéticas, contando com a disponibilidade de equipamentos e fármacos (MOORE; OGILVIE, 2001).

Das diversas modalidades de tratamento, a quimioterapia intralesional com fármacos antineoplásicos para casos não ressecáveis pode ser uma boa opção de tratamento, a mesma é capaz de fornecer uma concentração elevada e efeito prolongado do medicamento aplicado na lesão, entretanto, a opção de quimioterapia sistêmica é utilizada para alívio paliativo nos casos de lesões disseminadas ou metastáticas (KRAEGEL; MADEWELL, 2004).

A criocirurgia é outra modalidade de tratamento nos pacientes com carcinoma de células escamosas, sua principal aplicação é para tumores superficiais não invasivos com menos de $0,5 \mathrm{~cm}$ em diâmetro, e em áreas que as suturas são contraindicadas, bem como locais onde o acesso cirúrgico convencional não é indicado (DALECK; DE NARDI; RODASKI, 2009). Já em regiões comprometidas com massas tumorais com volume acentuado, profundas e invasivas, que não são removíveis cirurgicamente, se faz necessário o uso da radioterapia (KRAEGEL; MADEWELL, 2004).

A ressecção cirúrgica de carcinoma de células escamosas é instituída a fim de remover a maior quantidade de tecido comprometido com células neoplásicas, proporcionando margens cirúrgicas livres e ao mesmo tempo mantendo a função e a estética tecidual preservada (ROGERS, 1994). A técnica adotada para ressecção da neoplasia varia conforme a localização da lesão, casos que tenha comprometimento nasal realiza-se nosectomia, lesões em cabeça pode-se fazer o uso de flapes a fim de facilitar a cicatrização em virtude de a região apresentar quantidade de pele insuficiente para síntese de lesões extensas, já lesões em pina auricular é realizada a pinectomia (SCOTT; MILLER; GRIFFIN, 2001).

O tratamento dos carcinomas de células escamosas pode variar conforme o grau, tamanho e gravidade da lesão, no entanto, a principal maneira de evitar que os animais venham a apresentar este tipo de neoplasia é a prevenção, restringindo os animais a exposição aos raios ultravioletas e utilizando cremes bloqueadores solares (KRAEGEL; MADEWELL, 2004).

Em virtude da grande incidência de pacientes com carcinoma de células escamosas, o presente estudo objetiva relatar, a eficácia da nosectomia em sete felinos portadores de carcinoma de células escamosas. 


\section{Relato dos Casos}

Foram atendidos, 7 felinos, machos e fêmeas, entre 2012 e 2013 , sem raça definida, apresentando lesões em narina, em formato de couve-flor, ulcerada e de coloração avermelhada, consistência friável e com secreção nasal.

Após a coleta de um fragmento da lesão, de cada um dos felinos, com o auxílio de um punch, os fragmentos foram conservados em formol a $10 \%$ e o material foi encaminhado para exame histopatológico, que teve como resultado carcinoma de células escamosas.

Após o diagnóstico de carcinoma de células escamosas, os felinos foram submetidos à coleta de sangue para avaliação de hemograma e bioquímica renal (creatinina) e hepática (ALT e FA), a avaliação do risco cirúrgico foi completada com exame radiográfico torácico em três posições, (ventro dorsal e lateral direita e esquerda) para pesquisa de metástases em parênquima pulmonar, não sendo evidenciado imagem sugestiva de metástase; e avaliação cardíaca pelo ecocardiograma.

Em todos os casos, optou-se pela ressecção cirúrgica do plano nasal e de porção do lábio para aumento das margens cirúrgicas. Nos casos em que as margens se estenderam e dificultaram a síntese, foi realizada para correção do defeito com um flape de avanço da região do masseter ou da região frontal nasal, entre os olhos. À exérese do espelho nasal e do lábio foi realizada em forma de um retângulo, com o objetivo de favorecer a correção do defeito. Foi realizada juntamente a ressecção parcial do septo nasal.

Depois de criado o defeito, optou-se por estender as incisões paralelamente iniciando-se nos cantos do defeito e em direção ao masseter e a região cervical lateral direita ou esquerda ou da região frontal nasal, entre os olhos, dependendo do local de maior tensão cutânea. Cuidadosamente, foi realizada a divulsão com tesoura para não danificar os microvasos sanguíneos, visto que este flape apresenta padrão subdérmico. A extensão do flape foi proporcional ao tamanho (comprimento e largura) do defeito criado.

Após avaliar se o flape teria capacidade de cobrir o defeito inicio-se a sutura intradérmica em padrão simples continuo em toda sua extensão, com intuito de melhorar a coaptação das bordas de pele, utilizando fio Caprofyl 50®.

A síntese da pele foi realizada com fio, náilon 40, em padrão simples interrompido ou contínuo em toda a extensão do ferimento (Figuras 1 e 2). No pósoperatório foi prescrito Cloridrato de Ranitidina na dose de $2 \mathrm{mg} / \mathrm{kg} / \mathrm{BID}$, Cefalexina $30 \mathrm{mg} / \mathrm{Kg} / \mathrm{BID}$, Cloridrato de Tramadol $2 \mathrm{mg} / \mathrm{Kg} / \mathrm{BID}$ e Meloxicam $0,1 \mathrm{mg} / \mathrm{kg} / \mathrm{SID}$, para todos os felinos, assim como a utilização do colar elisabetano até a retirada dos pontos.

Durante o pós-operatório foi observado que todos os felinos apresentavam padrão respiratório normal, porém havia a necessidade de limpeza três vezes ao dia dos oríficios nasais, devido à formação de crostas sem interferência na respiração dos pacientes. Outro fator relatado no decorrer do pós-operatório, foi a dificuldade de higienização das narinas, visto que este procedimento era executado com auxílio de cotonete embebido por solução fisiológica, o que originava um desconforto e irritabilidade dos felinos, porém não houve a necessidade de tranquilização ou até mesmo sedação para tal procedimento.

Após quinze dias pós-operatórios os pacientes voltaram para avaliação e retirada dos pontos. Somente um paciente apresentou necrose na extremidade do flape do lado esquerdo, porém o mesmo recebeu alta do procedimento sem necessidade de nova intervenção cirúrgica. Neste paciente foi realizado debridamento do foco de necrose e submetido a tratamento tópico com pomada nebacetin ${ }^{\circledR}$. Dos sete felinos, dois pacientes apresentaram recidiva da lesão, e ambos foram tratados com quimioterapia adjuvante com bleomicina por via subcutânea na dose total de 5 UI, cada sete dias, num total de cinco semanas de forma paliativa na tentativa de controle do crescimento 
da lesão, visto que uma nova intervenção cirúrgica seria inviável devido a invasão tumoral. Destes dois felinos, um foi submetido à eutanásia e o outro continua em acompanhamento. Já os outros cinco felinos se encontram em acompanhamento póscirúrgico e sem evidências de recidiva local.

Figura 1. Sequência de fotos de nosectomia em um felino. A: Carcinoma espinocelular em narina. B: Lesão após tricotomia e higienização. C: Ressecção cirúrgica da lesão neoplásica, cartilagem nasal e estruturas adjacentes cutâneas (margem cirúrgica). D: Preparação do flape de avanço associado ao triângulo Burow. E: Remoção cutânea do triângulo. F: Divulsão e soltura do flape de avanço. G e H: reparo do defeito criado para ressecção cirúrgica. (Huppes R.).

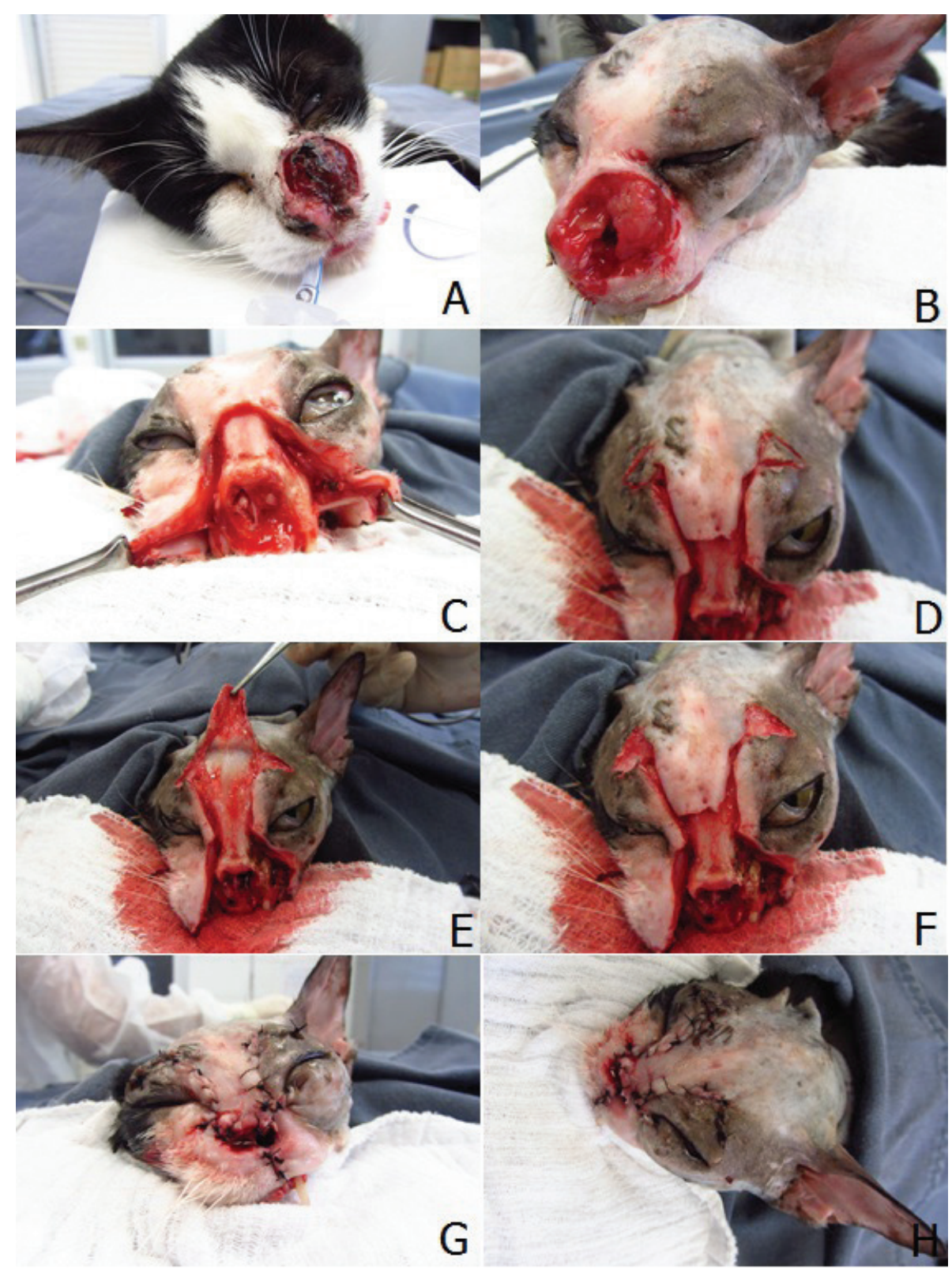

Fonte: Elaboração dos autores. 
Figura 2. Sequência de fotos de nosectomia em um felino. A: Carcinoma espinocelular em narina. B: Após ressecção do carcinoma espinocelular nasal e estruturas adjacentes. C e D: Preparação do flape de avanço. E, F e G: Aproximação cutânea com sutura intradérmica e cutânea em padrão simples interrompida G: Aspecto 21 dias após a cirurgia, retirada dos pontos. (Huppes R.).

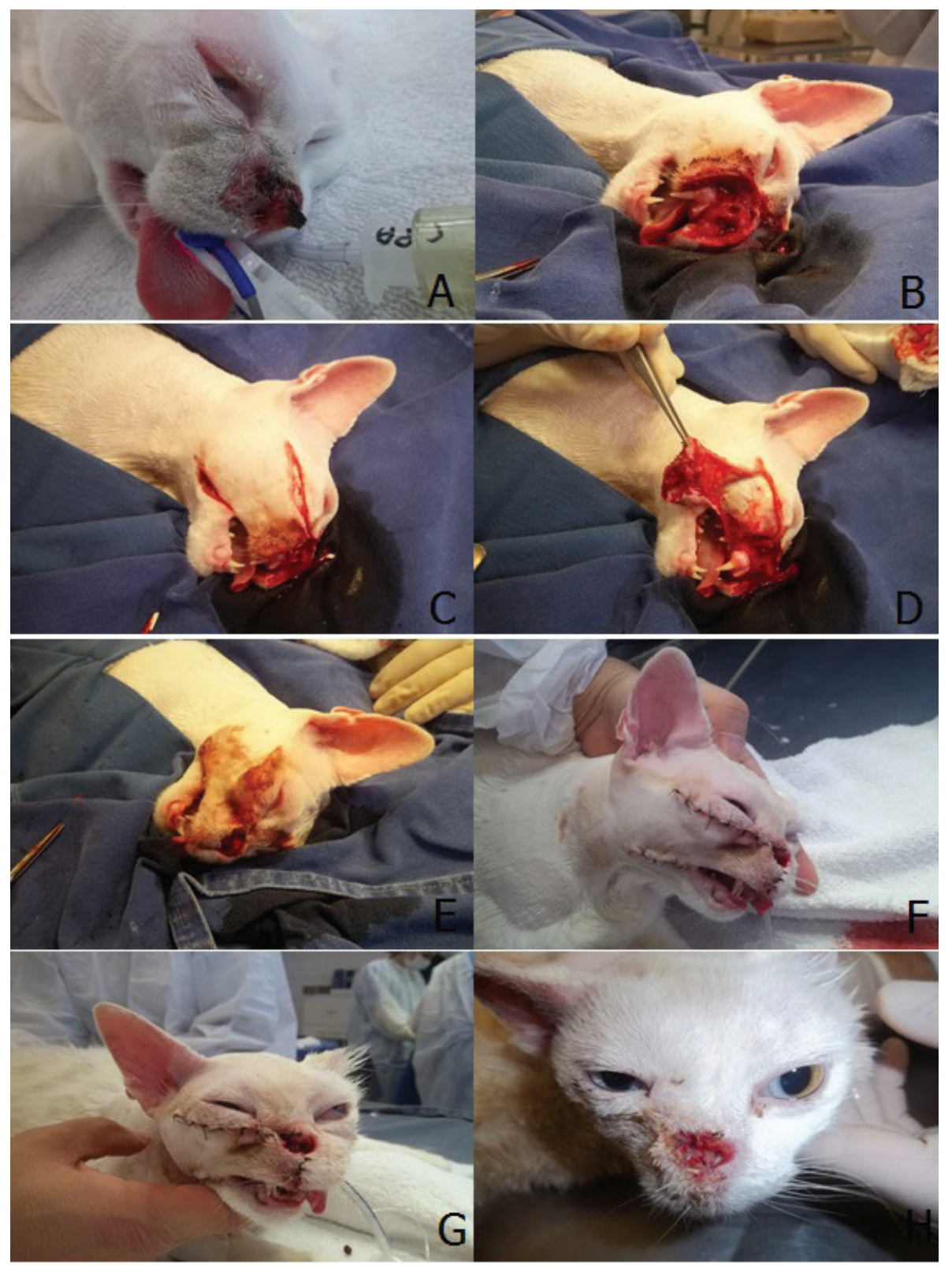

Fonte: Elaboração dos autores.

\section{Resultados e Discussão}

Segundo Barros et al. (2008) tratamentos cirúrgicos e crioterápicos costumam ser os mais indicados em casos de carcinoma de células escamosas, visto que este tumor possui baixa capacidade metastática.
Porém devido à extensão destas lesões nos setes felinos optou-se pela cirurgia e não pela criocirurgia no tratamento. Segundo Rogers (1994) a cirurgia é o melhor método de tratamento para os carcinomas espinocelulares, e ainda possui a vantagem de poder avaliar as margens cirúrgicas 
microscopicamente para garantir a excisão completa (KRAEGEL; MADEWELL, 2004). Além de se utilizar técnicas de cirurgia oncológica nos procedimentos cirúrgicos, devido a extensão e a necessidade de amplas margens se faz necessário utilizar técnicas de cirurgia reconstrutiva utilizando na sua maioria das vezes os flapes de avanço em padrão subdérmico para correção de nosectomias (PAVLETIC, 2003). Em nossos sete casos foram utilizados os flapes de avanço para recobrir o defeito da ressecção do tumor. Estas técnicas de avanço tem como principal finalidade cobrir defeitos cirúrgicos extensos com menor tensão na linha de sutura (PAVLETIC, 2003). Devemos lembrar que quando utilizamos as técnicas de flapes de avanço em padrão subdérmicos, devemos sempre que possível respeitar a proporção de um para um ou seja o flape deve ter o mesmo comprimento e a mesma largura do defeito a ser reparado (PAVLETIC, 2010). Ou ainda o comprimento do flape não pode exceder duas vezes a largura do retalho (STANLEY, 2007).

A criocirurgia segundo alguns estudos foi considerada a modalidade terapêutica menos efetiva quando comparada com a cirurgia e a radioterapia no controle local de carcinoma de células escamosas (BARROS et al., 2008). É sabido que a criocirurgia não deve ser utilizada como terapia primária em lesões maiores que $3 \mathrm{~cm}$. Além disso, não é recomendada sua utilização quando a mesma retarda a aplicação de outras modalidades de tratamento mais efetivas. No entanto, sua indicação permanece para casos de carcinoma de células escamosas in situ e para lesões pré-neoplásicas (MOORE; OGILVIE, 2001),

No entanto, em decorrência da agressividade da neoplasia, dois dos sete felinos apresentaram recidiva da lesão. É sabido que o prognóstico é menos benéfico após a excisão de lesões localizadas no nariz externo ou pré-maxila, devido ao alto índice de recidivas (RUSLANDER; KASERHOTZ; SARDINAS, 1997; STRAW, 1998).

Segundo Rodaski e Werner (2009), quando se institui o procedimento cirúrgico para ressecção da lesão neoplásica é necessário obter margens cirúrgicas livres a fim de evitar possíveis recidivas. Recomenda-se que a excisão cirúrgica seja realizada com margem de $1 \mathrm{a} 3 \mathrm{~cm}$ para o controle de eventuais recidivas. Entretanto, nestes casos não foi possível obter margens cirúrgicas compatíveis com as descritas por Rodaski e Werner (2009), em decorrência da localização das lesões, sendo este um agravante do procedimento cirúrgico.

O presente estudo vai de encontro com os resultados obtidos por Donner (1992), que relata o uso de flapes sendo bem empregado em lesões extensas e de difícil acesso, e quando se trate de tipos histológicos agressivos fica indicada a utilização de quimioterapia adjuvante após a ressecção da neoplasia. Nestes casos, em virtude da extensão e localização das lesões, se fez necessário a reconstrução cutânea devido a ressecção de parte do lábio, sendo assim optou-se por utilizar um flape em rolamento da região cervical lateral direita ou esquerda, dependendo do local em que houve maior extensão de diérese do lábio o qual favoreceu a correção do defeito obtido da cirurgia.

Segundo Rodaski e Werner (2009) vários protocolos podem ser empregados como terapia adjuvante em casos de carcinoma de células escamosas, como a doxorrubicina, actinomicina-D, bleomicina, carboplatina ou a utilização de antiinflamatórios inibidores seletivos de COX-2. Nestes dois casos em que houve recidiva, optou-se pela utilização da bleomicina devido a seu baixo índice de efeitos colaterais e eficácia citorredutora parcial nos carcinomas espinocelulares proporcionando um aumento de sobrevida em torno de quatro a seis meses.

\section{Conclusão}

Conclui-se que a nosectomia mostrou-se eficaz em cinco dos setes pacientes felinos, resseccionando a massa tumoral com margem, proporcionando um tempo de sobrevida aceitável, associado com qualidade de vida, o que é preconizado no tratamento 
dos carcinomas espinocelulares devido a sua baixa resposta aos tratamentos convencionais utilizados na rotina oncológica.

\section{Referências}

BARROS, R. M.; JACOBINA, G. C.; ECCO, R.; SILVA, C. E. V.; GALERA, P. D. Carcinoma das células escamosas multicêntrico em cão. Revista Brasileira de Saúde Produção Animal, Salvador, v. 9, n. 1, p. 103-108, 2008.

DALECK, C. R.; DE NARDI, A. B.; RODASKI, S. Oncologia em cães e gatos. In: RODASKI, S.; WERNER, J. Neoplasias de pele. São Paulo: Roca, 2009. p. 259-261.

DONNER, G. S. The role of surgery in the treatment of common tumors of the nose and mouth. Veterinary Medicine, Lenexa, v. 87, n. 10, p. 993-998, 1992.

FERREIRA, I.; CANEVESE, S. R.; FERREIRA, J.; PAGNI, T. C. Terapêutica no carcinoma de células escamosas cutâneo em gatos. Ciência Rural, Santa Maria, v. 36, n. 3, p. 1027-1030, 2006.

KRAEGEL, S. A.; MADEWELL, B. R. Tumores da pele. In: ETTINGER, S. J.; FELDMANN, E. C. Tratado de medicina interna veterinária. 5. ed. Rio de Janeiro: Guanabara Koogan, 2004. p. 555-557.

MOORE, A. S.; OGILVIE, G. K. (Ed.). Skin tumors. In: Feline oncology. Pennsylvania: Veterinary Learning Systems, 2001. p. 398-428.

MURPHY, G. F.; MARTIN, C.; MIHM, J. R. A pele. In: COTRAN, R. S.; KUMAR, V.; COLLINS, T. Patologia estrutural e funcional. 6. ed. Rio de Janeiro: Guanabara Kogan, 2000. p. 1048-1086.
PAVLETIC, M. M. Distant flap techniques. In: Atlas of small animal wound management and reconstructive surgery. 3.ed. Ames: Iowa, 2010. v. 1, cap. 12, p. 331-337.

. Pedicle grafts. In: SLATTER, D. (Ed.). Textbook of small animal surgery. $3^{\text {rd }}$ ed. Philadelphia: Saunders, Elsevier Science, 2003. p. 292-320.

RODASKI, S.; WERNER, J. Neoplasias de pele. In: DALECK, C. R.; DE NARDI, A. B.; RODASKI, S. Oncologia em cães e gatos. São Paulo: Roca, 2009. p. 254-297.

ROGERS, K. S. Feline cutaneous squamous cell carcinoma. Feline Practice, Santa Barbara, v. 22, n. 5, p. 7-9, 1994.

RUSLANDER, D.; KASER-HOTZ, B.; SARDINAS, J. C. Cutaneous squamous cell carcinoma in cats. Compend Contin Educ Pract Vet, Pennsylvania, v. 19, n. 10, p. 1119-1129, 1997.

SCOTT, D. W.; MILLER, W. H.; GRIFFIN, C. E. Muller \& Kirk's small animal dermatology. 6. ed. Philadelphia: W.B. Saunders, 2001.

STANLEY, B. J. Reconstructive surgery. In: CONGRESS OF THE WORLD SMALL ANIMAL VETERINARY ASSOCIATION, 32., 2007, Sydney. Proceedings... Sydney, Australia, 2007. Available at: <http://www.vin.com/proceedings/ Proceedings.plx?CID $=$ WSAVA2007\& Category $=299$. $6 \& \mathrm{PID}=18149 \& \mathrm{O}=\mathrm{Generic}>$. Accessed at: 03 maio 2009.

STRAW, R. C. Ressection of the nasal planum. In: BORJRAB, M. J.; SLOCUM, B.; ELLISON G. W. Current techniques in small animal surgery. 4. ed. Baltimore: Williams \& Wilkins, 1998. p. 343-346. 
